\title{
7. The European External Action Service: a melting pot of EU foreign policy practice
}

\author{
Elsa Hedling
}

\section{THE EUROPEAN EXTERNAL ACTION SERVICE}

The European External Action Service (EEAS), introduced in the 2009 Lisbon Treaty, plays a central but somewhat illusive role in European Union (EU) foreign policy. Formally established in the summer of 2010, the EEAS is the EU's first common diplomatic body tasked with supporting the EU's foreign affairs chief - the High Representative of the Union for Foreign Affairs and Security Policy and Vice-President of the European Commission (HR/ VP) - in conducting the EU's Common Foreign and Security Policy (CFSP). This common diplomatic service was established to strengthen the EU's role as a global actor, filling both an institutional and a strategic role in the EU's foreign policy architecture. The EEAS filled an institutional gap by centralizing the coordination of EU foreign policy. Moreover, the Lisbon Treaty significantly strengthened the role of the High Representative by adding a strategic role to the EEAS in the support of foreign policy leadership alongside the member states. These dual roles charged the EEAS with a challenging position: to coordinate member state foreign policy, and to exercise leadership by shaping and steering EU foreign policy.

Combining its institutional and strategic role has proved difficult, and assessments of the EEAS's autonomous role have not been overly enthusiastic (Furness, 2013; Vanhoonacker and Pomorska, 2013; Aggestam and Johansson, 2017; Aggestam and Bicchi, 2019). Despite the shortcomings in realizing its anticipated role, the EEAS has become an acknowledged player in EU foreign policy (Amadio Viceré et al., 2020). The EEAS performs functions that both complement and assist EU institutions and the member states in the everyday making of EU foreign policy. Its illusive role, however, rests in what its undefined central position means in practical terms and what results are expected. Because the EEAS is not an institution or an agency, it has an ambiguous posi- 
tion in the institutional landscape of the EU. In addition, no prerequisites exist for its common EU diplomatic service, and it was initially unclear how such a unique diplomatic corps would be composed to consolidate the state of EU diplomacy and member state diplomacies. Consolidating EU diplomacy meant forging a new diplomatic service of practitioners from multiple EU institutions and member states. This arrangement has made the EEAS the host of a melting pot of foreign policy practice, as it establishes knowledge and practices stemming from other organizational and national contexts while interacting with the evolution of a new institutional agency and culture. Finally, research on the EEAS's role in EU foreign policy continuously points to a gap between the EEAS's formal and informal practices (Helwig, 2017). Therefore, the EEAS lends itself to probing how processes and practices of both socialization and contestation continue to shape a new institutional body charged with the coordination of EU foreign policy.

In addition to its illusive characteristics, the EEAS is a contested player in EU foreign policy. From the outset, opinions about its purpose and effectiveness have often overshadowed attempts to analyse its gradual establishment. The EEAS has been the object of countless studies and debates attempting to assess the formal grounds of its legal and political role in the EU (De Baere and Wessel, 2015). These studies have predominantly focused on the challenges facing the EEAS in terms of realizing policy objectives or dealing with a crisis. The establishment of the EEAS coincided with uprisings in the Middle East and North Africa and the eurozone crisis, and later the refugee and Brexit crises (Barbé and Morillas, 2019). Although the series of crises challenged the task of foreign policy coherency, the EEAS's goals were stressed because of the urgency to overcome divisions among member states and internal threats of disintegration in the form of populism and Euroscepticism.

In realist and rationalist approaches, the central focus has been on the legal grounds and enacted autonomy of the EEAS vis-à-vis the member states. Such studies have often found that the limited room for the EEAS to manoeuvre, renders it a weak player in EU foreign policy (Kostanyan and Orbie, 2013; Furness, 2013; Dijkstra, 2017). The success of the EEAS depends on trust and commitment from both institutions and the member states. The absence of sufficient support from key stakeholders, and the difficult position between European foreign policy paradigms, continue to restrain the EEAS (Jørgensen et al., 2020). Moreover, the EEAS's impact on cohesion in EU external action remains debated (Gatti, 2021). But the EEAS cannot be understood as an organization or as an arena of EU foreign policy without considering the social melding of diplomatic processes and practices. Therefore, studies informed by social constructivism and practice theory have taken keen interest in the unique laboratory the EEAS offers to observe how norms, roles and identities 
have shaped common practices of EU foreign policy within it (Cross, 2011; Adler-Nissen, 2014b; Juncos and Pomorska, 2014; Bicchi and Maurer, 2018).

The gap between rationalist judgements of the weakness of the EEAS and its fertile soil for socialization serves as an intriguing example of how EU foreign policy is advanced despite contestation and lack of consensual agreement regarding rules and routines. Over the past decade, the EEAS has seen its practices develop as the result of the situated understandings and varied backgrounds and experiences of the practitioners. The routinization of these practices is gradually shaping a network of interaction among the sites where EU foreign policy is made (Bicchi and Maurer, 2018).

This chapter draws on recent constructivist and practice approaches to analyse the EEAS. The chapter situates the EEAS's role in EU foreign policy by focusing on the role of the HR/VP and the EEAS headquarters in Brussels. In addition, the chapter departs from the theoretical discussions in Chapter 4 to discuss the EEAS as a site for diplomatic practices and the particular conditions for socialization that follow from its unique composition. The findings presented in this chapter draw from academic books, articles and reports as well as official documents. The analysis is further developed through 27 interviews with officials in the EEAS conducted between December 2015 and April 2021.

This chapter demonstrates the value of studying practices as reflections of sense-making in the evolution of EU foreign policy in the EEAS. The EEAS coordinates practices that have resulted from a combination of the multiple organizational legacies as well as innovative responses to new situations. This interplay of organic evolution and strategic reflection is illustrated in a brief analysis of strategic communication practices that emerged in the wake of the 2014 Ukraine crisis. Similar processes of innovative response are likely to be witnessed in the aftermath of the COVID-19 pandemic (and discussed to some extent in Chapter 9). However, the practices that result from innovative response are more than adaptations made without consideration. That is, these practices are possible because the actors that engage in them are committed to making EU foreign policy work. This chapter contributes to the discussions on everyday practices cultivated in this book by approaching the EEAS as a melting pot of contestation and socialization in the field of European foreign policy. The chapter concludes with a discussion about how the analysis on the EEAS sheds new light on the role and nature of everyday practices in EU foreign policy.

\section{Is the EEAS a European Diplomatic Service?}

The EEAS is the EU's diplomatic service, but it is far from being equivalent to member states' ministries of foreign affairs (MFAs) as its role is shaped by the 
specific characteristics and idiosyncratic features of the EU's external action; most importantly, the continuous need to ensure that the external activities of the European Commission and the Council of the European Union are consistent (Juncos and Pomorska, 2020). Ensuring consistency is essentially an exercise in managing the intergovernmental and supranational tensions that have always characterized the EU integration process. As discussed in Chapter 2, the European Council is the main source of guidance in EU Common Foreign and Security Policy (CFSP). In addition, the Commission and the Council, and especially the Foreign Affairs Council (FAC), are tasked with specific mandates and follow the European Council's direction in their work. The EEAS is formally charged with assisting the HR/VP, who bridges the mandates of the Commission and the Council. Therefore, the EEAS is best described as a hybrid foreign policy service that oversees the complex processes of coordinating EU foreign policy.

The idea of a common diplomatic service has been debated in the EU since the very beginning but was not specifically articulated until the Maastricht Treaty in 1993. The introduction of the CFSP naturally led to questions about whether a common foreign policy could be delivered without a common foreign service. This was a sensitive question because it challenged member state sovereignty, and the majority view that external affairs should be kept in the intergovernmental pillar (Adler-Nissen, 2014b; Morgenstern-Pomorski, 2018). Nevertheless, as the EU gradually moved towards strengthening the capacity of a common EU foreign policy, arguments in favour of a common service gained influence. When the provisions of the CFSP were revised by the Amsterdam Treaty, which entered into force in 1999, the EU appointed its first High Representative (HR), Javier Solana. Although few formal powers of the HR were included in the Amsterdam Treaty, Solana was recognized as a high-profile EU foreign policy chief (Helwig, 2015, p. 90). The HR was formally tasked to assist the rotating president in CFSP affairs, but only when consistency (beyond the six-month presidency) was desired. This desire for consistency was the case during the war in Kosovo and the subsequent situation in the Western Balkans in the early 2000s where the EU required a more permanent interlocutor on the ground (Helwig, 2015). Solanas's role in the EU's Balkans policy gained the support of the Commission, paving the way for the establishment of the dual role of the position. However, the administrative tasks of the HR were a heavy burden for the General Secretariat of the Council of the European Union, and depended on Solana's informal network to mobilize resources and support, which further stressed the need for a foreign service (Duke, 2011a, p. 45).

The blueprint of the EEAS originated in the Convention on the Future of Europe (2001-2003), and a common diplomatic service was one of the more anticipated innovations in the failed Constitutional Treaty (2005). 
However, during the convention, the need for a common diplomatic service had been the subject of intense political debate between federalists and intergovermentalists; conflicts that could not be resolved, as no plan was presented for the composition and institutional role of the new service (Smith, 2013; Morgenstern-Pomorski, 2018). Although there was broad support for a common service, the proposal for transforming the HR into a Union Minister for Foreign Affairs was among the more contested ideas in the Constitutional Treaty (Adler-Nissen, 2014b). The Lisbon Treaty changed the federalist language but still extended the HR post significantly both in terms of formal competence (Vanhoonacker and Reslow, 2010) and in terms of symbolic leadership (Aggestam and Hedling, 2020).

\section{THE HR/VP}

The main task of the EEAS is to help the HR/VP fulfil their mandate. The formal powers and competences of this mandate are outlined in Article 18 of the 2009 Lisbon Treaty. The HR/VP is charged with ensuring the 'consistency and coherence of the EU's external action' with respect to the EU's Common Foreign and Security Policy (CFSP) and the Common Security and Defence Policy (CSDP), presiding over the Foreign Affairs Council (FAC), and striving 'for consensus on foreign policy priorities' (Lisbon Treaty, 2009, art. 18). The $\mathrm{HR} / \mathrm{VP}$ also represents the EU in international fora and international organizations on issues related to CFSP, leads the EU's diplomatic network of EU delegations, and heads the EEAS and the European Defence Agency (EDA), including their respective budgets (Koops and Tercovich, 2020). Since 2017, the EEAS and the EDA form the Secretariat of the Permanent Structured Cooperation (PESCO). In addition, the HR/VP is expected to attend regular meetings of the EU leaders in the Council and coordinate with the permanent President of the European Council. Another important change brought by the Lisbon Treaty is that the HR/VP in this role may initiate policy by submitting proposals both individually and with the support of the Commission.

The HR/VP must navigate the political pressure from several institutions, resisting pressure from member states as well as the Commission throughout the policy-making cycle. Although challenging, this is also an opportunity for EU foreign policy leadership, as the HR/VP has the ability to bridge the two worlds of EU external relations using the resources of the EEAS. Since its inception, the EEAS has been served by three HR/VPs: Catherine Ashton, Federica Mogherini and Josep Borrell Fontelles. These HR/VPs have approached their role and the EEAS leadership in different ways and therefore have influenced how institutional pressures are balanced and bridged in different ways. These differences are likely the result of different leadership styles as well as the different crises they had to manage (Koops and Tercovich, 
2020). Catherine Ashton's main task was to oversee the creation of the EEAS, a process that focused on seeking support from the member states to gain autonomy from the Commission (Koops and Tercovich, 2020). However, the second HR/VP, Federica Mogherini, focused on seeking support from the Commission rather than the member states (Pomorska and Vanhoonacker, 2016). The third HR/VP, Josep Borrell Fontelles, took office in December 2019 and was in his first year of service when charged with managing the COVID-19 pandemic. His leadership will be assessed against the coordination of unprecedented measures of crisis management (Amadio Viceré and Tercovich, 2020).

\section{THE HEADQUARTERS AND DELEGATIONS}

When the Treaty of Lisbon became operational on 1 December 2009, the most important new resource for the HR/VP was the promise of the EEAS (Helwig, 2015, p. 88). The Lisbon Treaty, however, did not provide details about the composition and functioning of the new organization, leaving this highly sensitive political issue unresolved. Article 13a (3) of the Lisbon Treaty, which relates to the establishment of the EEAS, offers only vague and imprecise stipulations regarding its composition and functions (Vanhoonacker and Reslow, 2010 , p. 2). In 2010, inter-institutional negotiations began that ultimately led to the adoption of the Council Decision 26 July 2010 (Council of the EU, 2010). The EEAS, which merged staff from both institutions and member states, became operational in January 2011.

The negotiations between proponents of the different political visions of the EU (and a fair amount of inter-institutional turf battles seeking to protect and promote their portfolios) resulted in the definition of the EEAS as a 'functionally autonomous body' (Morgenstern-Pomorski, 2018, p. 131). That is, the EEAS was an independent entity outside the influence of the Commission and the Council, with the legal capacity to perform its tasks and attain its objectives. Effectively, this meant that the consolidation of the management of EU foreign policy brought together competences from the previous two pillars of EU foreign policy. However, because the EEAS was not designated a legal entity, its organizational autonomy was limited (Blockmans and Hillion, 2013, p. 5). Nonetheless, the functional autonomy of the EEAS in the policy process grants a certain amount of functional agency to act autonomously (Juncos and Pomorska, 2020). The institutional position of the EEAS was settled before its inception, but the inter-institutional turf battles have to some extent continued to charge the relationship between the EEAS, the Commission and the Council. In addition, certain responsibilities overlap, which at times have caused friction. The Commission also managed to successfully retain key dossiers, such as external trade, which has resulted in important control func- 
tions over the EEAS (Aggestam and Bicchi, 2019). The relationship between the EEAS and the member states has also at times been strained, because of division among the member states in terms of enthusiasm towards the EEAS, and because of reluctance to hand over control of the foreign policy agenda. The member state MFAs have also signalled perceived competition with the EEAS (Adler-Nissen, 2014b).

The EEAS institutional design was inspired by the experiences of EU foreign policy-makers in other institutions, including best practices from foreign ministries and diplomatic services, defence ministries, crisis management agencies and even global corporations (Vanhoonacker and Reslow, 2010; Murdoch and Trondal, 2015; Juncos and Pomorska, 2020). The creation of the EEAS was realized by merging staff brought from the Commission, the Council Secretariat and the diplomatic services of the EU member states. In a first step, 60 per cent of the EEAS officials were brought from the Council Secretariat and the relevant departments of the Commission, foremost from the Directorate-General for External Relations (DG RELEX) and the Directorate-General for International Cooperation and Development (DG DEVCO). The officials from Brussels were complemented with new staff from the diplomatic services of the member states. The direction was to 'add meaningful presence', which would be reached when at least one-third of all staff came from the diplomatic services of the member states (Council of the EU, 2010/427/EU). This balance was reached less than three years after the EEAS was first established. A key concern during the establishment of the EEAS was to attract national diplomats, thereby balancing the dominance of officials from Brussels. The EEAS made efforts to recruit national diplomats by giving priority to these applicants for certain posts. Member states were also strongly encouraged to guarantee reinstatement in national foreign services after servicing in the EEAS. It was also deemed important to achieve fair geographical representation (Adler-Nissen, 2014b) and gender balance (Chappell and Guerrina, 2020). The recruitment process, however, strongly built on pre-existing procedures and selection processes employed within the Commission, which had implications for the composition of EEAS staff (see Murdoch and Trondal, 2015; and the next section). The initial size of the EEAS, which has a staff of 3720, was modest in the EU's institutional landscape, which employs more than 50000 people, and was comparable to the foreign service of a medium sized-member state (Balfour and Raik, 2015, p. 167). Since 2011, the EEAS has seen steady growth due to both budgetary expansions and increased staff provided by member states.

The organizational structure was also inspired by past experiences. The EEAS headquarters in Brussels is organized as follows: large departments (directorates) for major regions of the world; multilateral and thematic affairs; administration, budget, security and communication; a crisis management 
directorate with civilian planning capability; and the Military Staff and Situation Centre. These divisions are overseen by managing directors, an institutional legacy from the DG RELEX in the Commission (see Smith, 2013). In addition to supporting the EU's external representation through the delegations and the HR/VPs representative tasks, the EEAS is involved in the planning, implementation and assessment of the Common Security and Defence Policy's (CSDP) operations and missions (see Chapter 9).

In addition to its headquarters, EEAS includes more than 130 EU delegations (previously Commission delegations) in non-member countries and international organizations. Although the EEAS is organized very differently than MFAs, the delegations do have a similar role to that of an embassy (Duquet, 2018). The upgrade from Commission delegations to comprehensive EU delegations has also strengthened European cooperation in third countries (Bicchi and Maurer, 2018). The delegations consist of staff from the EEAS and other institutions, most notably from the Commission. The specific dynamics and practices within and between the EU delegations are explored in greater detail in Chapter 8.

Since 2012, the EEAS's offices have been in the Triangle building on Schuman roundabout located across the street from the Commission, located in the Berlaymont building. The European Parliament had originally proposed that the EEAS be housed within the Commission, but the member states had insisted on autonomy and independence (Juncos and Pomorska, 2020). When the second HR/VP, Federica Mogherini, was invited by the then new President of the Commission, Jean-Claude Juncker, to take on a more pronounced role in the Commission, she moved her cabinet to the Berlaymont building (Aggestam and Hedling, 2020), a symbolically important move.

\section{POLICY INFLUENCE}

Much like its institutional partners, the roles and practices of the EEAS have gradually developed, and the autonomy and agenda-setting role of the EEAS is still to be decided. Analyses have demonstrated that the EEAS can exert some influence on the EU foreign policy process (Dijkstra, 2017; Morillas, 2020) and project a more visible role for the HR/VP (Aggestam and Hedling, 2020), although its leadership is perceived to be limited (Aggestam and Johansson, 2017). Some of this influence has been less formal and depends on the entrepreneurial use of the EEAS's central position, its coordinating role, access to informal networks, and the epistemic communities on the ground (Bicchi, 2012; Bueger, 2016; Delreux and Keukeleire, 2017). Although the support of the member states has been divided and has fluctuated some over time, the Council has gradually delegated more tasks to the EEAS, such as in the case of the Ukraine crisis (Cross and Karolewski, 2017; Natorski and Pomorska, 
2017). It has also been suggested that the Commission's and MFAs' complaints of lack of leadership may in fact reflect awareness of the issue, and will lead to more influence (Adler-Nissen, 2014b). Furthermore, the enhanced role of the EU delegations has also made it more influential (see Bicchi and Maurer, 2018; and Chapter 8).

\section{FORGING A NEW ORGANIZATIONAL IDENTITY}

The remainder of this chapter seeks to answer how we can explain and understand the production of EU foreign and security policy, understood as an expanding repertoire of actions undertaken by the EU in this field, by learning from the unique context of the EEAS. The development of the EEAS has been of great interest to scholars of socialization. To some, it was to be the great experiment of the socializing potential of EU integration (Cross, 2011). In terms of prescriptive socialization, the EEAS has been disappointing. Although it has delivered on its promises to develop a new model of EU diplomacy (Duke, 2013), it has not been able to foster a true 'esprit de corps' (Juncos and Pomorska, 2014). While to some this is a failure, it has led others to conclude that its organizational culture is one forged by intergovernmental and inter-institutional compromises (see Bátora, 2013; Lequesne, 2015b) and that this has produced 'a diplomatic service of different speeds' (Austermann, 2014).

\section{Identities and Belongings}

The EEAS may be described as a hub of EU diplomacy that hosts multiple institutional identities and belongings. Its institutional culture cannot be transferred or reproduced from other institutions, nor be modelled on any national institution. Rather, EEAS culture is being forged out of intergovernmental and inter-institutional compromises (Lequesne, 2015b) and a melding of epistemic communities (Spence, 2012). At the organizational level, the EEAS has had to balance different administrative cultures. Whereas DG RELEX and DG DEVCO were shaped in the hierarchical structure of the Commission, the Council Secretariat was smaller, with a flat organizational structure (EEAS-9, 2016). The military staff, on the other hand, brought stricter codified procedures and reporting lines (Spence, 2012; Onestini, 2015, p. 74). In addition, the EU Special Representatives (EUSR) are not employed by the EEAS but answer to the HR/VP, and the diplomats from the foreign services of member states brought their own organizational experiences and expectations. This amalgamation has resulted in the hosting of several communities of practice with little or no interaction between them. For example, although the sections for Civilian Planning and Conduct Capability (CPCC), European 
Union Military Staff (EUMS) and the Situation Centre (SITCEN) were fully transferred to the EEAS from the Council Secretariat, their practices remained largely unchanged (EEAS-20, 2018; EEAS-26, 2021). Lequesne (2015b, p. 5) has suggested that some of these units form 'a world of [their] own inside the EEAS'. Furthermore, the interaction between these communities has often depended on the previous experience of staff; that is, someone with previous experience in the CPCC would bring their knowledge and networks to new 'islands within the EEAS' (EEAS-27, 2021).

The organizational fragmentation is also expressed in the lack of agreement of the EEAS's role in relation to the member states. The EEAS is often described as either being 'complementary to' the member states (Austermann, 2014) or 'in service to' them (Maurer and Morgenstern-Pomorski, 2018). A similar subtle but important distinction is often made by officials at the EEAS, who either stress the complementary role of the EEAS, the ways in which it fills a gap, or the way that it provides support to the member states. This distinction does not necessarily represent institutional backgrounds, as both national diplomats and officials in Brussels reference the member states as the only decision-makers in matters of EU foreign policy (EEAS-3, 2016; EEAS-8, 2016; EEAS-20, 2018). Rather, this distinction often reflects the experience of effectiveness in the EEAS, or lack thereof. Informants with experience of ineffective processes and bad practices often excuse this by referencing the lack of clear directives from the member states (EEAS-22, 2018; EEAS-24, 2019). EEAS officials who spoke about success stories instead highlight the important complementary role the EEAS fills in relation to the member states (EEAS-9, 2016; EEAS-11, 2016; EEAS-23, 2018; EEAS-25, 2020). This lack of agreement of the exact role of the EEAS reflects the absence of an established shared institutional identity by trying to legitimatize its purpose. It is, however, clear that the staff reflect on their identity and the role of the EEAS, signalling a process of contestation and negotiation over a shared understanding.

At the organizational level, the EEAS has been challenged to establish and communicate a set of 'traffic rules' that can organize the intergovernmental and inter-institutional 'mess' (EEAS-17, 2018; EEAS-26, 2021). The fact that the hierarchy of the EEAS's functions reflect more of an institutional network than a single institutional structure has added to the urgency of establishing routines and policies that bring more clarity (Carta and Duke, 2015).

At the level of social groups, the complexity runs even deeper. Previous research has found that officials in the EEAS differ greatly across professional backgrounds, experience, values and worldviews (Bicchi, 2012; Juncos and Pomorska, 2013, 2015). Most notably, there is a stark contrast between the identities of EU career bureaucrats and member state diplomats (Lequesne, 2015a, p. 46). This divide raised questions during the recruitment process to 
the EEAS, where some claimed that despite welcoming 'Brussels outsiders', the recruitment process and selection criteria favoured technical expertise over diplomatic experience (Murdoch and Trondal, 2015, p. 108). Staff coming from the national foreign services had concerns regarding the staffing of the EEAS. For example, they noted that the officials in Brussels favoured technocratic approaches to external relations because they were not trained as diplomats (Juncos and Pomorska, 2015).

The divide between diplomats and techno-experts was also a result of organizational ambiguity, but this ambiguity has gradually improved through the development of practices 'where everybody knows what role to play' (EEAS-5, 2016; EEAS-9, 2016). It also reflected initial prejudice that was not necessarily deeply rooted in the social relations. For example, in the first years of Federica Mogherini's tenure, EEAS officials referred to her as 'the Italian' and the staff she brought as 'the Italians', even though some of them had technocratic backgrounds brought from Brussels and were in fact not Italian (EEAS-3, 2016). When asked about this, officials had little to say and explained it as 'mostly talk before we knew what was actually happening with the new leadership' (EEAS-20, 2018) and that 'there was a fear that she was bringing the Italian perspective' (EEAS-19, 2018). Despite the evident challenges to the development of a shared organizational culture, officials in the EEAS identify with the EEAS and increasingly share the common goal of wanting EU foreign policy to work (Juncos and Pomorska, 2013, 2014, 2015).

Another dimension at play in the EEAS has been the verbalized pressure to socialize. Since the first discussion of a common diplomatic service, a shared organizational culture or even a 'common identity' has been an outspoken challenge, and to many an ultimate goal (Spence, 2012; Juncos and Pomorska, 2014). Officials in the EEAS are perhaps among the most well-informed respondents about theories of socialization, to the point that they may exaggerate or intentionally undermine the role of social interactions in their daily work. Considering Juncos and Pomorska's findings of a shared identity and the desire for the EEAS to work, one can also expect this pressure to lead to role-playing (Adler-Nissen, 2014b; see Chapter 4).

\section{EEAS Practices of EU Foreign Policy}

The multiple identities and belongings have naturally led to new habits of coordination developing slowly. Typically, diplomats react slowly to change, but in the case of the EEAS, officials have often expressed a desire to react but have been constrained by the structure within which they operate (EEAS-14, 2017; EEAS-23, 2018; EEAS-26, 2021). EEAS officials have little influence over the formal constraints regarding the mandate, but in terms of learning the ropes and developing working routines, emphasis has been put on training, 
which is essentially an opportunity for learning. In this regard, 'learning by doing' is not only about training new staff in an organization but also about finding ways to foster 'an environment for socialization and professionalization' (Cross, 2011, p. 463). When officials felt that they were unable to initiate new practices, learning processes were a way to make first moves, because 'at least then we can get a conversation going and identify if and where we have different understandings' (EEAS-15, 2018).

Lequesne has suggested that practices in the EEAS relate to three main functions: coordinating the positions of the various agents involved in the EU foreign policy-making; providing added value information on foreign policy; and promoting new ideas (Lequesne, 2015a, p. 8). The EEAS performs coordination through a process that involves both the EU member states and the institutions, most notably with the Commission, a process realized through the formal and informal practices that have gradually established a system of EU coordination. The rule that EEAS officials chair the Political and Security Committee (PSC) and the Council Working Groups (CWGs) is essentially a formal practice (see Chapter 5 and 6), as well as the coordination practices among the EU delegations (see Chapter 8).

Many of the EEAS's coordination practices have gradually been formalized through developed habits that avoid overstepping the mandate (EEAS-3, 2016). Coordinating the multiple directions of EU foreign policy without clear understanding of who does what has emphasized informal consultation practices and 'routines for testing the grounds' (EEAS-8, 2016). This process of coordination through careful probing has benefited from the composition of EEAS staff, the in-house knowledge of different working practices across the institutions, and the formalizing of new coordination practices by the member states. An EEAS official talked about understanding the added values of other people's experiences as the most important learning experience: 'you have to be able to understand and accept when you are not the best person to send to meetings and how to be smart about how we work with the different perspectives that we have in here' (EEAS-21, 2018).

In terms of providing added value information on foreign policy, the EEAS has significantly changed and expanded the practices of sharing information on EU foreign policy (Bicchi, 2012). Sharing information, however, remains sensitive to member state resistance. Member states are reluctant to give up control over information processes that are important symbolic diplomatic resources (Adler-Nissen, 2014b). In addition to the formal systems of information-sharing, the EEAS also facilitates less informal training opportunities for the member states, centred around best practices and discussions of the practical implementation of cooperation as means to improve the internal communication in EU foreign policy. The EEAS Crisis Response and Operational Coordination Department responsible for the activation of 
the EEAS Crisis Response System (Crisis Platform, EU Situation Room, and Crisis Management Board) has worked actively, for example, to improve information-sharing practices throughout the various phases of a crisis life cycle. EEAS officials refer to these training events as 'positive experiences of sharing and learning from each other. It is not about us training them, it's about the learning opportunity for all of us' (EEAS-20, 2018). During these meetings, opportunities are also given 'to talk about when cooperation on the ground worked well, and when it didn't' (EEAS-21, 2018).

Finally, the promotion of new ideas is an area where EEAS practices of EU foreign policy agenda-setting remain contested. Although the HR/VPs want to exhibit more active leadership, initiatives have often been limited to a strategic narrative rather than effective leadership (Aggestam and Hedling, 2020). Rather than seen to be exercising true leadership, the HR/VP and the EEAS are engaged in practices of shared leadership based on horizontal and informal practices (Aggestam and Bicchi, 2019). Innovating EU foreign policy is still a matter left to the member states. The EU Global Strategy (EUGS) launched in June 2016 was an opportunity for the second HR/VP, Mogherini, to shape future EU foreign policy, at least rhetorically (Aggestam and Hedling, 2020; Morillas, 2020). The process of formulating a strategy and its launch was anticipated with caution by EEAS officials (EEAS-8, 2016; EEAS-12, 2016). They expressed the need for strategic discussions to overcome their challenges, especially following Ashton's perceived lack of interest, but acknowledged that the member states would need to 'buy in' for it to be a meaningful exercise (EEAS-2, 2016; EEAS, 6-2016; EEAS-7, 2016; EEAS-15, 2018). Nevertheless, there was anticipation that a more vocal external strategy would serve as an internal road map towards an enhanced role for the EEAS. The process of formulating the strategy differed from the previous strategy delivered by Solana in 2003, as it was more inclusive and more transparent (Aggestam and Hedling, 2020). This included both new practices of coalition-building and outreach. In the process of drafting the strategy, Mogherini established a working group that included representatives from the EEAS, the Commission, the Council Secretariat and the European Council (Tocci, 2017). She also engaged the member states by touring Europe and beyond to encourage broad participation in strategic reflection. The EUGS was therefore accompanied by a number of new practices for the promotion of new ideas. It also sparked several new initiatives such as the Civilian CSDP Compact (CCC) and the Permanent Structured Cooperation (PESCO), which both aimed at strengthening and increasing efficiency in areas of civilian and military cooperation. Although created in connection to the EUGS, both the CCC and PESCO are the result of informal practices of member state coalitions, and were formally initiated only after informal written proposals were circulated (EEAS-25, 2020). 


\section{EMERGING PRACTICES: THE CASE OF STRATEGIC COMMUNICATION}

The EEAS is a flexible organization that has developed gradually through learning but also through adaptation and responses to external situations. The EEAS is flexible by default for two main reasons. The vague and unprecise language in reference to its form and functions in the Lisbon Treaty left it vulnerable to political pressure in its inception and early development (Morgenstern-Pomorski, 2018). This lack of clarity with regard to its role in EU foreign policy has been used by both institutions and member states to shape and control its future. But perhaps more importantly, the EEAS is flexible because its institutional legacy of EU foreign policy cooperation has evolved gradually over time, rendering it institutionally prepared to respond (although not always rapidly) and to develop during new challenges. In the specific case of the EEAS, new situations have also become opportunities for development without the constraints of previous institutional legacies and risks of overlapping practices. The rise of an EU model for strategic communication offers a brief illustration of the emergence of new practices resulting from new situations in need of a speedy response (Hedling, 2021).

When the EEAS was launched in 2010, three people operated the EEAS unit for strategic communication. In 2015, when the member states gave the HR/VP and the EEAS a mandate to organize a response to Russia's disinformation campaign (EU Council, 2015), a process to transform communication practices from within began (Hedling, 2021). By then, it had become clear that Russian disinformation was targeting the EU. The FAC tasked the HR/VP with developing a plan on how to respond. The HR/VP was not given a budget and was restricted to using existing resources. The combination of a new mandate, budgetary constraints, and contestation and resistance from some member states, led to experimentation (EEAS-8, 2016). It was decided that the EEAS would first develop a task force and recruit new competence by asking willing member states to contribute with suitable experts.

In September 2015, the EEAS had an operative task force - the East StratCom Task Force - consisting of nine journalists and strategic communication experts with little or no experience with diplomatic culture. This new group, with new dispositions from 'the outside', were now developing new EU-specific practices of countering disinformation (EEAS-1, 2015; EEAS-2, 2016). In this role, the East StratCom Task Force not only challenged traditional practices of diplomatic communication but also challenged the institutional legacies of the EEAS. The process of experimentation resulted from the rational calculation to avoid 'socialized diplomats' and 'Brussels communicators' and to bring in new people with other backgrounds and new 
perspectives to develop 'completely new practices' (EEAS-8, 2016; EEAS-9, 2016; EEAS-15, 2018). EEAS officials described this rationale as the result of the opportunity presented by the new mandate to overcome some of the informal problems they were experiencing as a result of staff thinking from the point of view of their previous position. This was a way of 'using the momentum to start fresh' (EEAS-17, 2018). The officials' reflections on how to best introduce practical change resemble a process of 'problematization', where actors identify what the challenges are and how they can be addressed (Bueger and Edmunds, 2021, p. 175).

The first months of the East StratCom Task Force entailed substantive brainstorming, and the newcomers were instructed to 'be creative' and 'explore what can be done' (EEAS-3, 2016). This process included mapping the formal and informal rules in the EEAS to discover whether and how new ways of doing things could be introduced. For example, they discovered that writing something on a website would require several levels of clearance, 'but you could put almost anything on Twitter' (EEAS-3, 2016). The East StratCom Task force introduced a new set of practices that revolved around using digital media to raise awareness of disinformation among EU citizens through strategic communication. In doing so, they generated attention not only for their group but also for the EEAS as the producer of a common foreign policy response vis-à-vis Russia (Wagnsson and Hellman, 2018). In less than four years, the task force developed from an unfinanced initiative to a prioritized unit (Hedling, 2021). These practices also spread within the EEAS. There are two additional task forces that engage in similar activities to counter digital disinformation. Since 2015, the EEAS has significantly enhanced its capacities for strategic communication. By 2018, the newly titled Strategic Communications Division had grown to include 51 staff. In a relatively short time, these new practices of EU diplomatic communication became regarded as a successful model of strategic communication that foreign services of member states 'can and want to learn from' (EEAS-19, 2018; EEAS-20, 2018; EEAS-24, 2019). The transformation of communication practices has also spilled over into the general practices of diplomatic communication (European Parliament, 2019). This suggests that these practices are no longer emergent or new, but have become settled and recognized in a shared repertoire of best practices.

This brief illustration of countering disinformation through strategic communication as emerging practices in the EEAS demonstrates that practical change may reflect both intentional transformation and organic evolution (Hedling, 2021). In this case, the problematization of existing social belongings in the EEAS led officials to favour a more experimental approach by bringing in new staff who could produce new practices (cf. Bueger and Edmunds, 2021). 


\section{CONCLUSIONS}

The EEAS is a unique organizational context. Even if we disregard the sui generis characterization of EU foreign policy, there is no equivalent to the EEAS. Many attempts of capturing the unique character of the EEAS have been preoccupied with its legal competences and degree of autonomy from the Commission and the Council, but the EEAS has also intrigued spectators as a unique social context in EU foreign policy. Irrespective of the EEAS effectiveness in terms of policy influence and leadership, it has established as an organization in the Brussels landscape that hosts a social mix of national diplomats and EU civil servants. As such it has become an increasingly attractive environment for European diplomats to engage in and learn from the everyday making of EU foreign policy. Moreover, as the research front points towards an increasing complexity in the practices of EU foreign policy governance post-Lisbon (Aggestam and Bicchi, 2019; Amadio Viceré and Tercovich, 2020), the EEAS is likely to continue to evolve its everyday practices rather than reconfigure its institutional structures. By way of conclusion, three remarks can be made regarding everyday practices in the EEAS.

First, the EEAS has hosted a socialization process that has not necessarily produced the outcome one would expect from such a perfect setting for a natural experiment of EU socialization. It was anticipated that the EEAS could be transformed to a successful institution that would cultivate new norms and lead to a distinctive institutional identity (Cross, 2011, p. 448). Ten years after its inception, the EEAS is still fragmented with multiple social identities among its staff that hinder norm internalization in its truest sense. Despite this, EEAS officials speak of collective efforts to make it work by learning how to work together to fulfil the purpose of the EEAS. In this sense, officials share a common normative conviction. Although learning to navigate the maze of informal practices within the EEAS takes time, newcomers appear to adopt the belief in the common service relatively fast. Therefore, rather than a successful experiment, the EEAS continues to be a laboratory, not just for testing theories of international relations, but also for learning about the practices of EU foreign policy-making.

Second, although socialization is largely absent in the identities of the EEAS staff, there is growing agreement and shared understanding around emerging practices of EEAS diplomacy. Practices of EEAS diplomacy form a network of inherited practices, merged practices from previous institutional legacies, and emerging practices that have developed organically through both deliberate reflection and experimentation. Although the anticipated development of crisis management practices is still hindered by member state reluctance to delegate, 
and the slowness of the EU foreign policy process, other less traditional areas of foreign policy have produced new repertoires of practices.

Third, the EEAS exhibits an interplay between practices and socialization that can best be described as multiple processes that continue to produce both sustained contestation and gradual practical habituation of common practices. What is perhaps particularly interesting in the context of the EEAS is that this combination appears to have become institutionalized, to the point where their productive tensions contribute to further the development of EU diplomacy. A central part of learning the ropes in the EEAS constitutes navigating these areas of contestation through coping practices. As such, the EEAS exhibits social learning that we have explained as changing norms, rules and procedures on the basis of newly shared practical understandings (see Chapter 4). In addition to learning as an internal logic of EEAS, practices of learning have also become a strategy in the relationship to the institutions and the member states that guides practices of coordination. By focusing on promoting opportunities to learn, cohesion through learning, and the legitimation of experimental learning, the EEAS has managed to establish an actively passive role in EU foreign policy. 